\title{
The Effect of Customized Woven and Stacked Layer Orientation on Tensile and Flexural Properties of Woven Kenaf Fibre Reinforced Epoxy Composites
}

\author{
A. Hamdan, ${ }^{1,2}$ F. Mustapha, ${ }^{1,2}$ K. A. Ahmad, ${ }^{1,2}$ A. S. Mohd Rafie, ${ }^{1,2}$ \\ M. R. Ishak, ${ }^{1,2}$ and A. E. Ismail ${ }^{3}$ \\ ${ }^{1}$ Department of Aerospace Engineering, Faculty of Engineering, Universiti Putra Malaysia, 43400 Serdang, Selangor, Malaysia \\ ${ }^{2}$ Aerospace Manufacturing Research Centre (AMRC), Level 7, Tower Block, Faculty of Engineering, Universiti Putra Malaysia, \\ 43400 Serdang, Selangor, Malaysia \\ ${ }^{3}$ Department Engineering Mechanics, Faculty of Mechanical and Manufacturing Engineering, Universiti Tun Hussein Onn Malaysia, \\ 86400 Batu Pahat, Johor, Malaysia
}

Correspondence should be addressed to A. Hamdan; radenahars@gmail.com

Received 2 October 2015; Revised 27 January 2016; Accepted 1 February 2016

Academic Editor: Yiqi Yang

Copyright (C) 2016 A. Hamdan et al. This is an open access article distributed under the Creative Commons Attribution License, which permits unrestricted use, distribution, and reproduction in any medium, provided the original work is properly cited.

The synthetic fibres have created some issues including risk of inhalation during fabrication process, renewability, biodegradability, and recyclability in composites industry. The usage of biocomposites as a replacement to synthetic fibres is beginning to be widespread. However, it is noted that lesser attention has been devoted to evaluating the mechanical properties of woven kenaf composites at various woven and stacked layer orientation. Thus, the research objective is to identify the effect of woven and stacked layer orientation on tensile and flexural properties of kenaf composites. Two types of fibre orientation are employed; type A contains a higher yarn density and type B contains a low yarn density. The tensile and flexural tests are conducted to analyze the mechanical properties of woven kenaf fibre composites and compare them to random chopped kenaf composites. The fracture interface between fibre and matrix epoxy is further investigated via scanning electron microscope. Type A kenaf improved up to $199 \%$ and $177 \%$ as compared to random chopped kenaf for flexural strength and tensile strength, respectively. Scanning electron microscopy analysis shows that resin matrix is properly induced into kenaf fibre gap hence giving additional strength to woven kenaf as compared to random chopped kenaf.

\section{Introduction}

The usage of synthetic fibres like glass fibre and carbon fibre has created some issues including risk of inhalation during fabrication process, renewability, biodegradability, and recyclability. The replacement of synthetic fibres with biocomposites fibres in Fibre Reinforced Plastics (FRP) is beginning to be widespread [1]. Research done in biocomposites reveals several types of natural fibres including flax $[2,3]$, bamboo [4], pineapple [5], jute [6,7], and kenaf [710]. The mechanical properties in natural fibre may differ due to several factors such as fibre morphology, structure density, cell wall thickness, woven or unwoven [11], and length and diameter of the structure [12]. Kenaf is one of the natural fibres which is extensively used and has proven to provide significant advantages in various industries, including the automotive industry [11-16]. A few parts in cars such as the bumper beam and dashboard can be replaced with kenaf fibre. Hybrid kenaf/fibreglass has shown being an alternative to the existing glass mat thermoplastic products [13].

Several researches on kenaf composites have already been conducted such as analysis studies on the effect of chemical treated on kenaf $[17,18]$, fibre fraction $[8,19]$, woven orientation [17,20,21], hybrid effect [13], and resin application $[7,10,22,23]$. A few elements are highlighted in the study that influence the mechanical properties of natural fibre such as the volume fraction, the interfacial adhesion of the fibre with the matrix, and orientation of the fibre and 


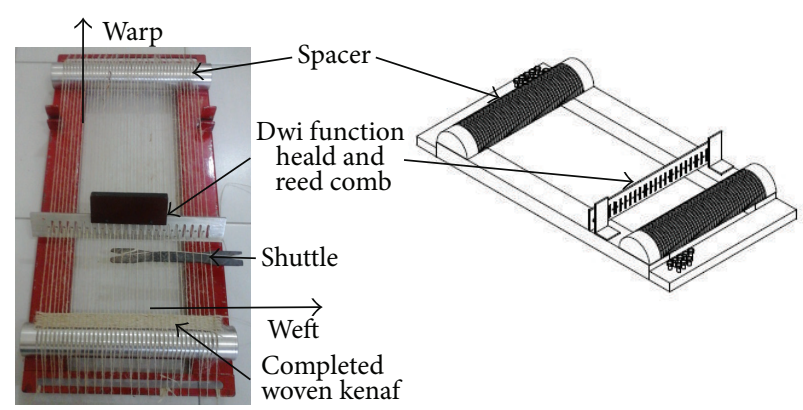

Figure 1: Self-design handloom.

length of the fibre $[18,24]$. These reports are summarized in Table 1.

Previously, most of the studies done on the woven form of textile composites were on synthetic rather than natural fibre [20]. Besides that, the yarn size is various for each study. Moreover, the studies done on natural fibre usually employed random orientation and compressed mat [20]. It is also noted that lesser attention has been devoted to evaluating the mechanical properties of woven kenaf composites at various woven and stacked layer orientation for smaller yarn fibre size.

Therefore, this research is focused on examining the effect of woven and stacked layer orientation on tensile and flexural properties of kenaf composites. In this research, a smaller yarn size is applied as compared to previous researches $[17,19,21]$. Thus, different yarn size and woven orientation are proposed. The woven kenaf is arranged at different stacked layer orientation also. The proposed woven orientation and stacked layer orientation are presented in the Experimental Setup. Epoxy resin is employed to produce kenaf composites plate.

\section{Experimental Setup}

2.1. Plate Sample Preparation. Random chopped kenaf fibre and kenaf yarns fibre were utilized for this research. Kenaf yarn was supplied by Juteko Co. Ltd., Bangladesh, and random chopped kenaf fibre was supplied by KIRD Enterprise. The yarn fineness value is recorded as 300 tex. The size is smaller compared to Hani et al. (2013) and Yahaya et al. (2014). The matrix used was epoxy type EpoxAmite 100 (Smooth-on) and cured with 102 Medium Hardener (Smooth-on). Physical properties of EpoxAmite 100 and 102 hardener combination from the manufacturer are as shown in Table 2.

Epoxy resin was employed as it has light weight and less damage to the manufacturing equipment and has better mechanical properties compared to the other resin [18]. Kenaf yarn was weaved manually using self-designed handloom. Figure 1 shows the self-designed handloom employed in weaving imbalanced plain woven kenaf. Weft and warp setup for woven kenaf was 11 ends per centimeter or 28 epi (ends per inch) and 3 picks per centimeter or 8 ppi (picks per inch), respectively, as shown in Figures 2 and 3.

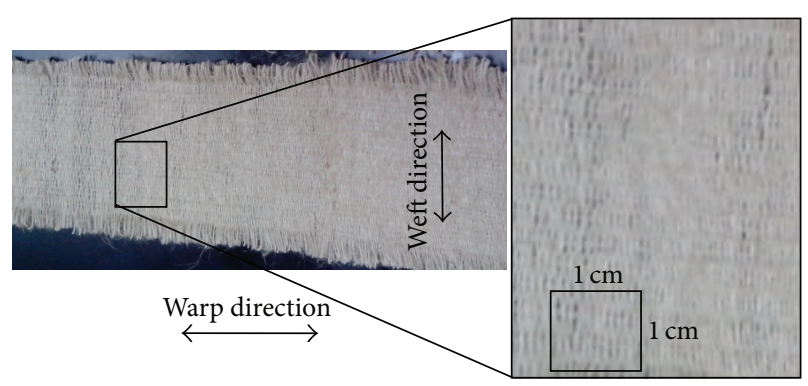

FIGURE 2: Completed woven kenaf.

The kenaf weaving process can produce maximum size $20 \mathrm{~cm} \times 25 \mathrm{~cm}$ of woven kenaf. The fabrication of woven and random chopped kenaf composites plates was conducted via vacuum infusion process. The ratio between kenaf and epoxy resin was 30:70 and it was cured for 12 hours. Meanwhile, the resin was prepared at the ratio of epoxy to hardener, $100 \mathrm{~g}: 28.4 \mathrm{~g}$. Three layers of woven kenaf were stacked at average $70 \mathrm{~g}$ in overall weight. For random chopped kenaf, $70 \mathrm{~g}$ kenaf short fibre is set up on the fabrication mould. In this testing, there were five different samples fabricated. Four woven kenaf composites samples were differentiated from woven waft and weft orientation as shown in Table 3 and Figure 4 for sample 1, Figure 5 for sample 2, Figure 6 for sample 3, and Figure 7 for sample 4. Random chopped kenaf is fabricated as a control sample. The woven and stacked layer orientation is presented in Table 3.

2.2. Flexural Test. The flexural test was conducted from a 3point loading using Instron 3365 testing machine according to ASTM D790-03. The rectangular samples of dimension $127 \mathrm{~mm} \times 12.7 \mathrm{~mm}$ were cut using circular saw. The tests were conducted at the crosshead displacement rate of $45 \mathrm{~mm} / \mathrm{min}$. The reports were automatically generated by the software embedded in the machine's computer. For each sample, five specimens were tested at room temperature and the average was taken as a final result.

2.3. Tensile Test. Tensile test was conducted to determine the stress-strain behaviour of the woven kenaf composites. The test was carried out using 810 Material Testing Machine (MTS) based on ASTM D3039 on plates with a size of $200 \mathrm{~mm} \times 25 \mathrm{~mm}$ and $3.5-4.5 \mathrm{~mm}$ sample thickness for each composite. The samples were carefully cut from the laminate using wheel saw and finished to the accurate size. 500 psi grip pressure was applied to the samples. A standard head displacement at a speed of $2 \mathrm{~mm} / \mathrm{min}$ was applied. For each sample, five specimens were tested and average results were recorded.

The results were compared with previous research findings to identify the effect of fibre orientation to the flexural and tensile properties of woven kenaf.

2.4. Scanning Image Microscopy Analysis. In order to study the morphological feature of fibre matrix interface on woven kenaf and mechanical testing failure surface, the surfaces 


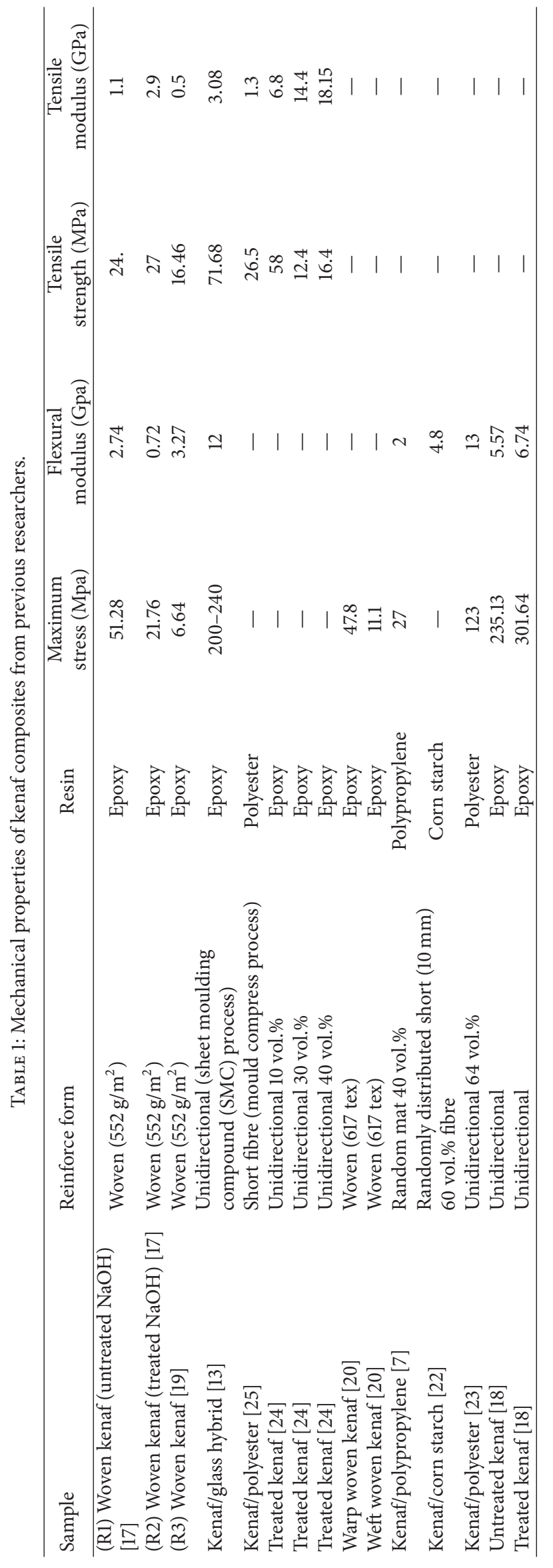




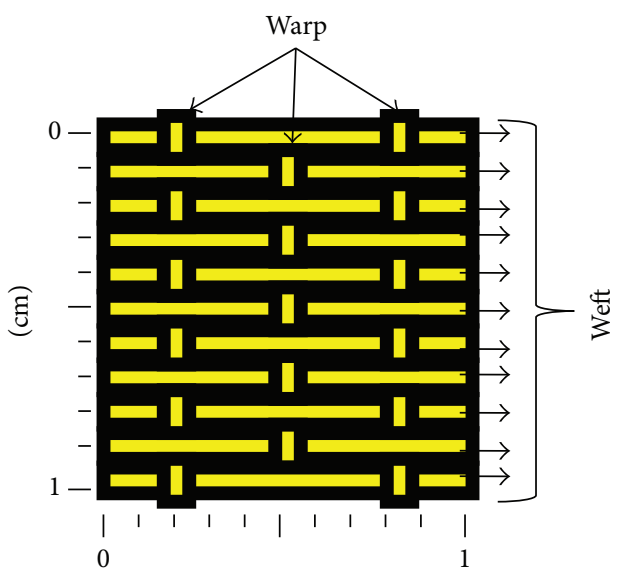

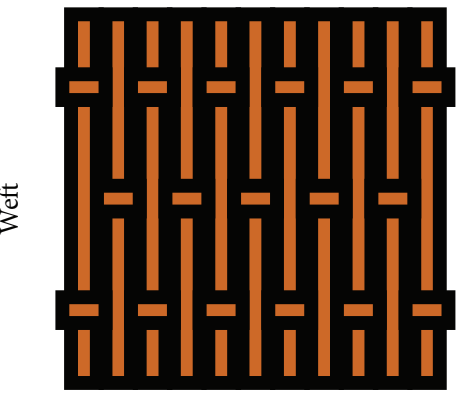

(a)

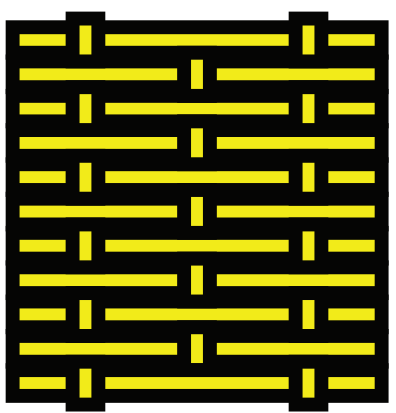

(b)

$(\mathrm{cm})$

FIgURE 3: Schematic of kenaf woven orientation. (a) Orientation A, (b) orientation B.

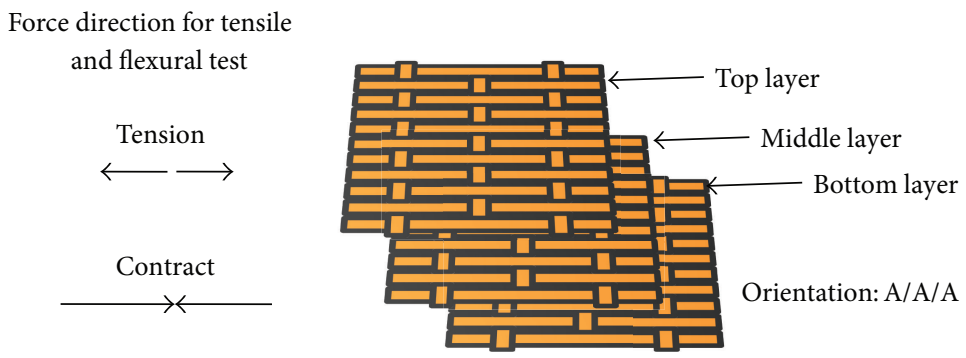

Figure 4: Sample 1: orientation A/A/A.

TABle 2: Physical properties of combination of EpoxAmite 100 and 102 hardener.

\begin{tabular}{lcc}
\hline Physical properties & PSI & Pa \\
\hline Flexural strength (ASTM D790) & 12,220 & $84.25 \times 10^{6}$ \\
Flexural modulus (ASTM D790) & 423,000 & $2.91 \times 10^{9}$ \\
Ultimate tensile strength (ASTM D638) & 8,180 & $56.40 \times 10^{6}$ \\
Tensile modulus (ASTM D638) & 450,000 & $3.10 \times 10^{9}$ \\
\hline
\end{tabular}

TABLE 3: List of samples employed at different orientation for mechanical properties testing.

\begin{tabular}{lc}
\hline Sample & Orientation \\
\hline S1 & A/A/A \\
S2 & B/A/B \\
S3 & A/B/A \\
S4 & B/B/B \\
S5 & Random chopped kenaf \\
\hline
\end{tabular}

of the samples were examined using a scanning electron microscopy (SEM) (Hitachi model SU1510). Prior to the test, the samples were cut into $10 \mathrm{~mm} \times 10 \mathrm{~mm}$ and adhered on aluminium plate. The image was focused at 140 times magnification.

\section{Result and Discussion}

3.1. Flexural Properties. The flexural properties results are shown in Figures 8-10. A flexural test was conducted to determine the strength of materials to withstand bending forces before breaking point. The maximum load for each sample's orientation is depicted in Figure 8. It exhibits that S1 experienced the highest maximum load. It is followed by S3, S2, S4, and S5. The density of weft yarn is believed to increase the strength of each layer. In woven kenaf, a low density in warp direction may contribute to the lower strength of kenaf composites as demonstrated in S4. Random chopped kenaf shows the lowest strength as short fibre kenaf has the lowest bonding among the fibre. Figure 9 exhibits the stress-strain curve for each sample. S1 exhibits the highest flexural strength, highest elongation break, and highest flexural modulus.

The results for flexural strength and flexural modulus are shown in Figure 10. Generally, woven kenaf composites indicate a higher flexural strength and flexural modulus as compared to random chopped kenaf composites. S1 presents the highest flexural strength at $127.47 \mathrm{MPa}$. It is followed by S3, S2, S4, and S5 with 116.30 Mpa, 60.98 MPa, 48.07 MPa, and $42.67 \mathrm{MPa}$, respectively. There is a $9 \%$ increment on flexural strength between S1 and S3. Meanwhile, S1 woven kenaf composites show 199\% increment on flexural strength compared to random chopped kenaf composites. The flexural modulus for S1, S2, S3, S4, and S5 is 7.5 GPa, 3.7 GPa, 6.6 GPa, 


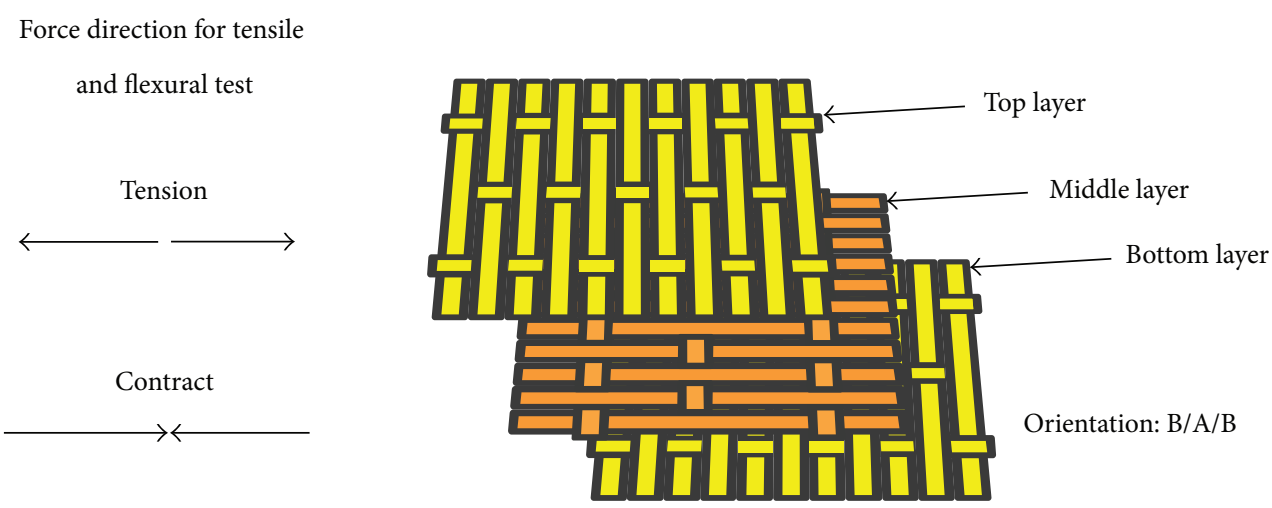

Figure 5: Sample 2: orientation B/A/B.

Force direction for tensile and flexural test
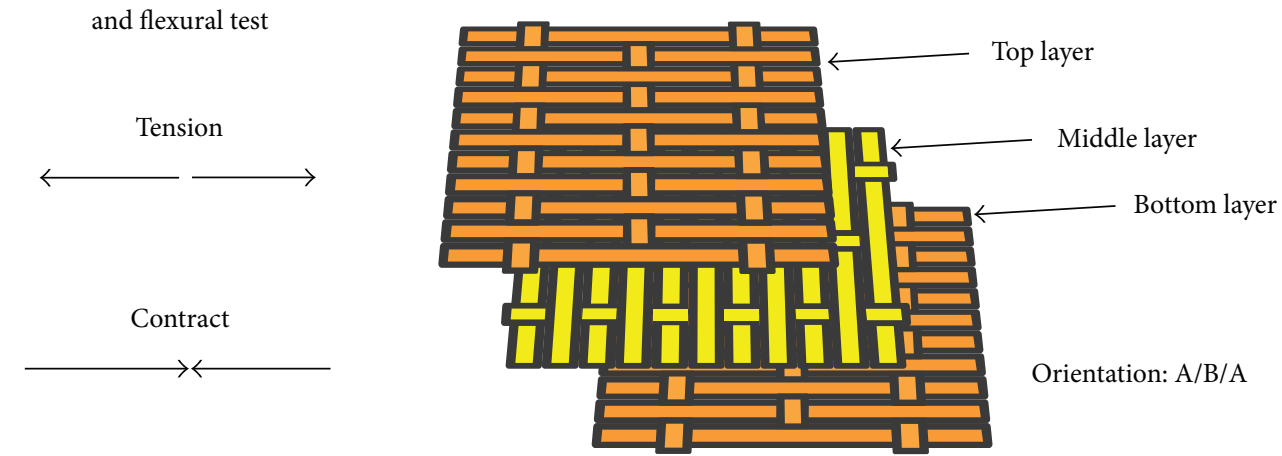

Figure 6: Sample 3: orientation A/B/A.

Force direction for tensile
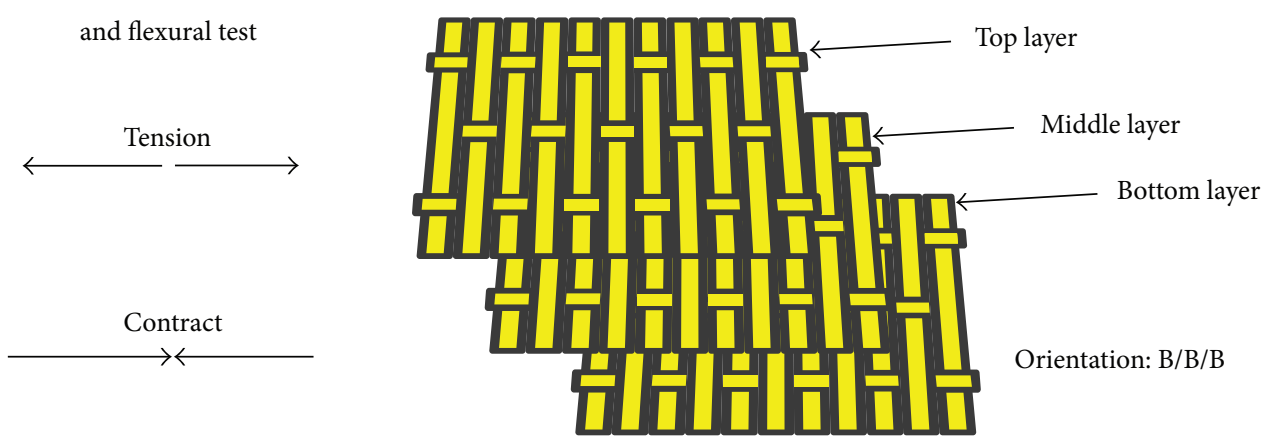

FIGURE 7: Sample 4: orientation B/B/B.

3.1 GPa, and 2.7 GPa, respectively. S1 shows the highest flexural modulus compared to the lowest value, S5. Woven kenaf improved up to $178 \%$ as compared to random chopped kenaf. The difference in increment between S4 and S2 is 19\%. Significant increase in percentage occurred between S2 to S3 and S3 to S1 which are $78 \%$ and $14 \%$, respectively. In flexural test, a compressive mode occurred on the top layer while the bottom layer experienced tensile force [21].

In the flexural test, the compressive mode was found to be the main cause of failure of the top layer sample [21, 26]. The difference in fibre orientation in each layer may vary the flexural strength of each sample. The result indicates that woven kenaf composite has shown significant improvement compared to the random chopped kenaf composites. Besides, the woven yarn fibre orientations clearly effect the material strength. The A orientation exhibits a higher strength compared to the $\mathrm{B}$ orientation. This may due to a higher yarn density which can support and resist the force exerted at transverse direction of the sample.

$\mathrm{S} 1$ indicates the highest strength as the sample is supported by three layers of type A orientation. This is followed by $\mathrm{S} 3$ which covers two layers of type A orientation. S2 is 


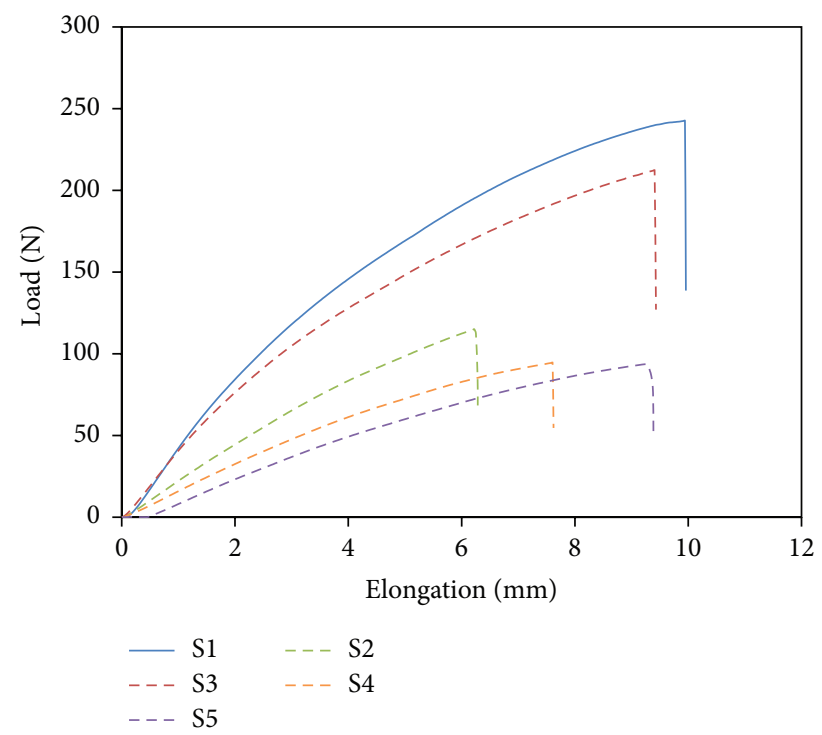

FIGURE 8: Flexural-load elongation curves for kenaf composites.

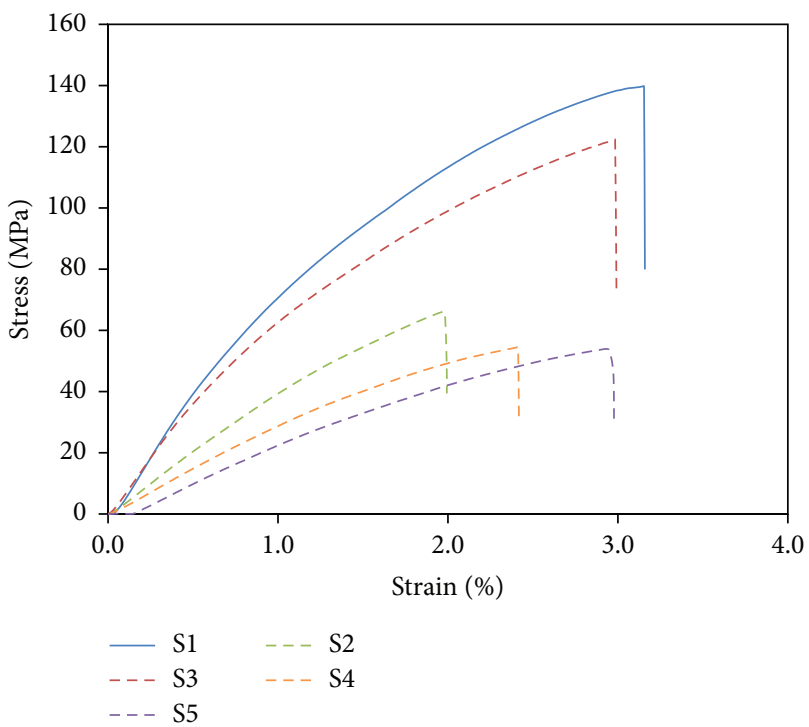

FIGURE 9: Flexural-stress-strain curves for kenaf composites.

higher than $S 4$ as it lays one type A compared to $\$ 4$ which only employs type B layer. In stacked layer orientation analysis, $\mathrm{S} 1$ is proposed as the best combination layers. Type A layer performs higher strength and gives advantages to S1 followed by S3. In type A orientation, each centimeter is supported by eleven yarn fibres. Meanwhile, type B orientation only is supported by three yarns' fibre at the direction of contract and tensile.

Furthermore, flexural strength and flexural modulus comparison with resin properties supplied by the manufacturer as shown in Table 2 reveals positive findings. Flexural strength and flexural modulus show increment percentage to $51 \%$ and $157 \%$, respectively, when compared to $\mathrm{S} 1$ as the highest value. It shows that yarn fibre orientation and layer

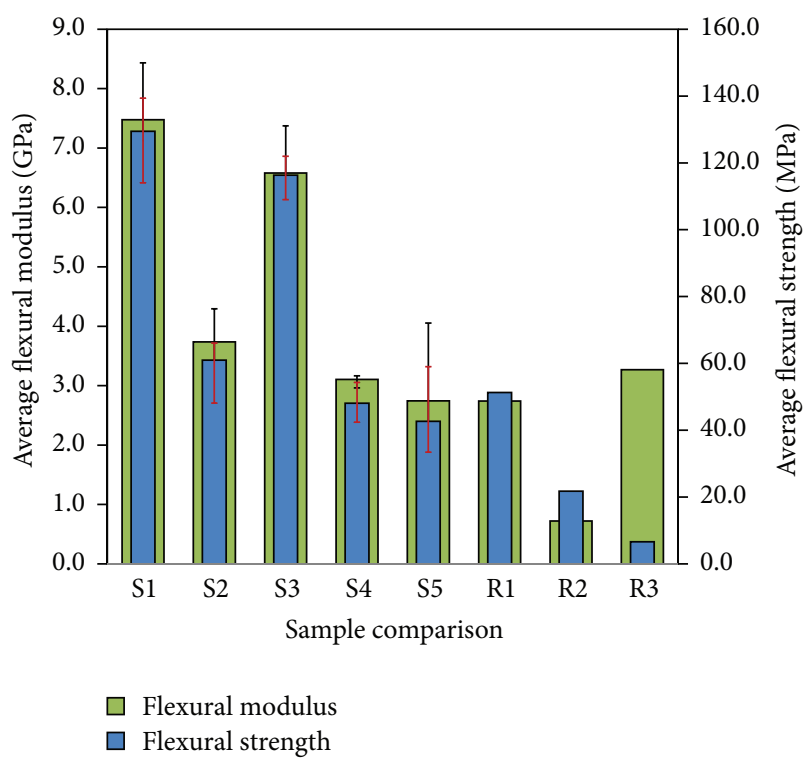

FIgURE 10: Flexural modulus and flexural strength of kenaf composites.

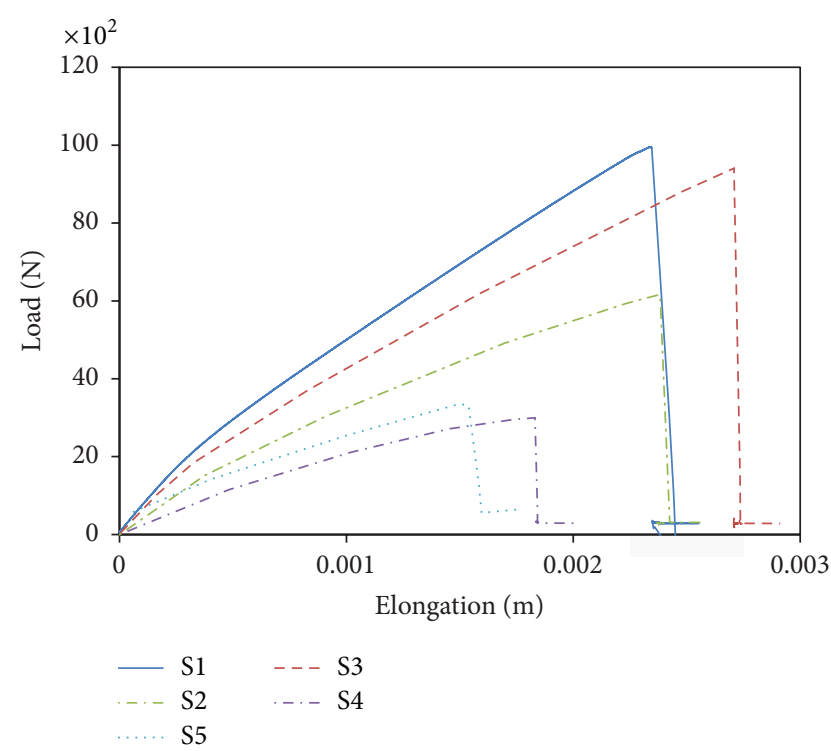

FIGURE 11: Tensile-load elongation curves for kenaf composites.

arrangement in S1 perform excellent improvement especially in flexural strength and modulus.

3.2. Tensile Properties. Tensile properties are illustrated in Figures 11-13. Figure 11 exhibits the maximum load resisted by the material before it breaks. S3 shows the highest elongation resistance and S1 presents the highest load resistance. Figure 12 shows the stress-strain curve which indicates the ultimate tensile strength at maximum graph and tensile modulus for graph gradient. Tensile modulus and strength represent the ability of material to resist with any tensile deformation. The results for tensile strength and tensile modulus are reported in Figure 13. 


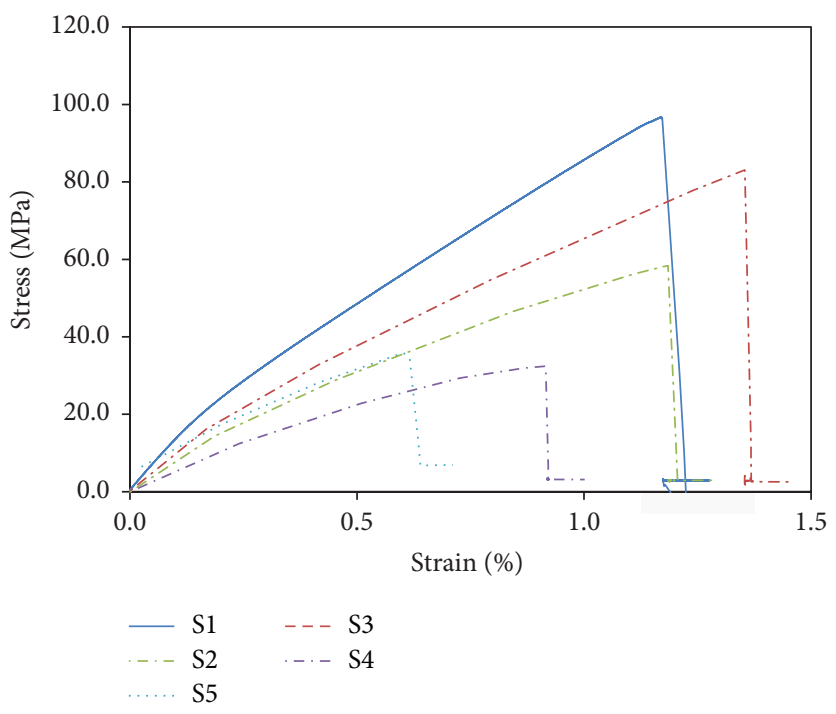

FIgURE 12: Tensile-stress-strain curves for kenaf composites.

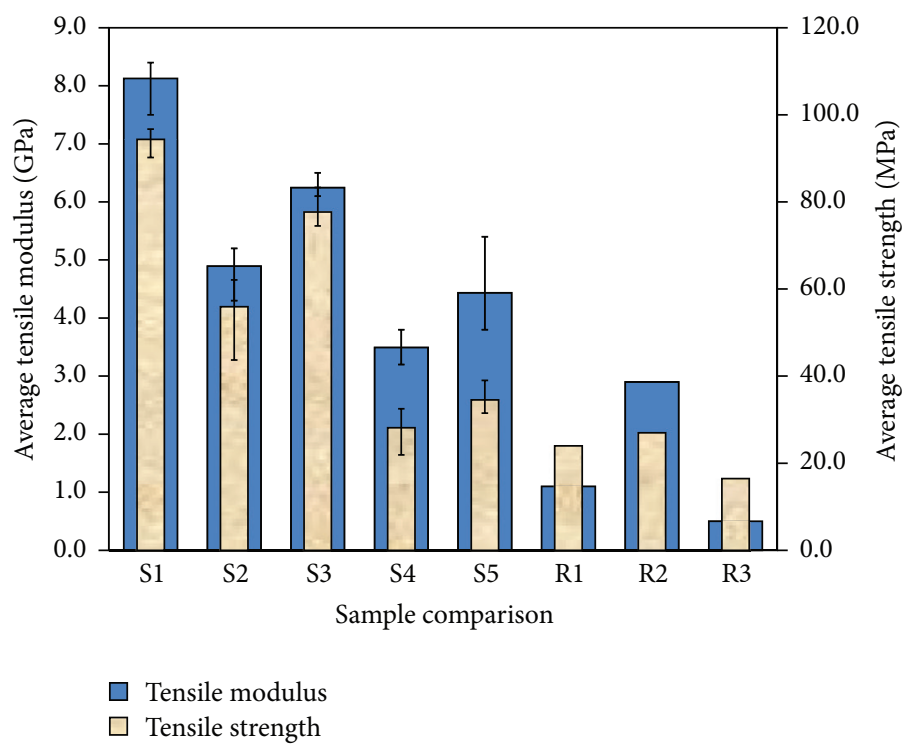

FIGURE 13: Tensile modulus and tensile strength of kenaf composites.

Tensile modulus and tensile strength illustrate similar trends. S1 exhibits the highest tensile strength and tensile modulus, followed by S3, S2, S5, and S4. The values for tensile strength are $94.3 \mathrm{MPa}, 77.7 \mathrm{MPa}, 55.9 \mathrm{MPa}, 34.0 \mathrm{MPa}$, and 28.1 for S1, S3, S2, S5, and S4, respectively. Tensile modulus for S1, S3, S2, S5, and S4 is $8.1 \mathrm{GPa}, 6.2 \mathrm{GPa}, 4.9 \mathrm{GPa}, 4.4 \mathrm{GPa}$, and $3.5 \mathrm{GPa}$, respectively. Generally, woven kenaf composites are better than random chopped kenaf composites except for S4. An increase in thickness may cause decrease on tensile strength irrespective of fibre orientation [19]. The average thickness of S4 is $3.7 \mathrm{~mm}$ while S5 is $3.4 \mathrm{~mm}$. An $8 \%$ difference may cause decrease of tensile strength for $\mathrm{S} 4$ as compared to S5. S1 shows an improvement of tensile strength and modulus compared to $\mathrm{S} 5$ at $177 \%$ and $84 \%$, respectively. In woven kenaf composites, yarn fibre orientation clearly exhibits a huge influence on the tensile properties. S2 improved 99\% for tensile strength and $40 \%$ for tensile modulus, respectively, compared to S4. Improvement from S2 to S3 is about 39\% and $26 \%$ for tensile strength and tensile modulus, respectively. Lastly, S1 is improved compared to S3 at $21 \%$ and $31 \%$ for tensile strength and tensile modulus, respectively. This shows that the highest number of yarns in each woven area exhibits better tensile and flexural properties.

Besides that, the ultimate tensile strength and tensile modulus results are compared with resin properties shown in Table 2. Similar to flexural test analysis, flexural strength and flexural modulus of $\mathrm{S} 1$ showed increment as compared to resin properties. This trend supports the improvement produced due to yarn fibre orientation and stacked layer arrangement orientation. 


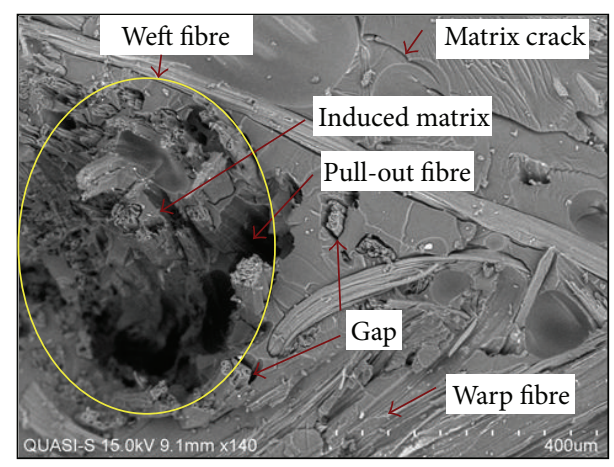

FIGURE 14: SEM analysis on woven kenaf composites.

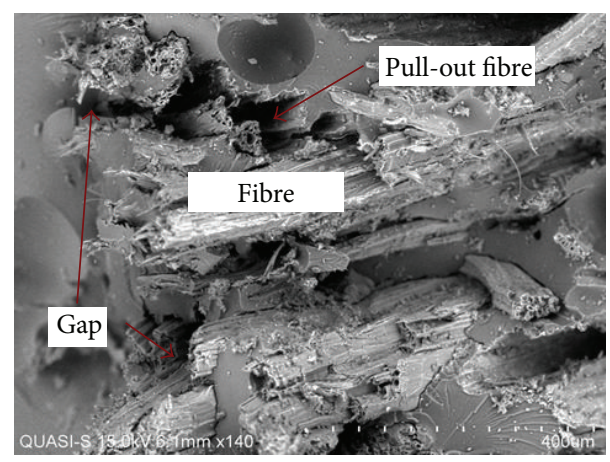

FIGURE 15: SEM analysis on random chopped kenaf composites.

3.3. Scanning Electron Microscopy Analysis. Figures 14 and 15 depict the fibre morphology of woven kenaf composites and random chopped kenaf composites, respectively. The analyses were conducted on flexural samples which had undergone a compress effect on the top layer and a tension effect on the bottom layer. Generally, both figures show that interaction between fibre and matrix is a bonded interaction without resin penetration occurring into the fibre. There are obvious gaps seen in both figures indicating poor bonding interaction between fibre and matrix resin.

Figure 14 shows that the resin matrix is induced into the kenaf fibres gap. Hence, it gives additional strength and a bigger bonding surface area between resin and fibre as compared to random chopped kenaf composites. Figure 15 shows that the fibre sizes are mixed and randomly arranged. The big fibre may decrease the bonding surface area hence decreasing the bonding strength. The fracture mechanisms occurring for woven and random chopped kenaf composites are pulled out, detached, and debonded from epoxy matrix as depicted in the figures. The matrix crack occurring is revealed in the composites as shown in Figure 14.

Besides that, further analysis is conducted on type A (sample 1) and type B (sample 4) orientation. Figure 16 shows the SEM analysis at three different points near the fibre. The microstructure at break point was investigated and elucidated. It shows that the resin is properly diffused inside the fibre, hence making the strength increased. Furthermore, the fracture mechanism occurring is pulled out and detached. No gap or air bubble effect on the composites is noticed.

Figure 17 shows the SEM analysis on type B or sample 4. Generally, gap is observed in the picture. It may cause the strength reduction. The fracture mechanism occurring exhibits pulled out and debonded mechanism. Air bubble can be spotted at several areas in resin region.

3.4. Comparison Properties. Several previous papers on woven kenaf composites indicate findings on tensile and flexural properties as shown in Table 1. Three results from Table 1, namely, R1, R2, and R3, are compared in Figures 10 and 13. Group S indicates the samples testing in this research. Group R presents several findings reported from previous researches. The main difference between group $\mathrm{R}$ and group $S$ is on yarn fibre orientation, yarn size, and stacked layer orientation.

This research is proposing new yarn fibre orientation from 300 tex size of yarn fibre kenaf. S1 as the optimum stacked layer orientation is compared with group R in terms of flexural and tensile analysis. Generally, group $S$ shows better result as compared to group $\mathrm{R}$ for tensile and flexural properties. The flexural strength for $\mathrm{S} 1$ has improved by $152 \%$ compared to R1 (the highest in group R). Meanwhile, there was an improvement of $127 \%$ for S1 compared to R3 (the highest in group R) for flexural modulus. Similar trend occurred in tensile properties. S1 improved to $250 \%$ and $179 \%$ for tensile strength and tensile modulus respectively as compared to the highest value in group $\mathrm{R}$. This result exhibits that small size of yarn produces a higher yarn density for each woven area given a better finding on tensile and flexural properties. Indirectly, vacuum infusion process is reported to give more advantages compared to hand lay-up process for woven kenaf composites. However, unidirectional type fibre tends to exhibit outstanding mechanical properties compared to woven kenaf composites as shown in Table $1[18$, $23,24]$. The volume of fibre in each area of kenaf may affect and influence the mechanical properties of kenaf composites [24]. Higher volume fibre exhibits better flexural and tensile properties for natural fibres.

The yarn size and woven orientation influenced the performance of stacked layer orientation in woven kenaf composites. The finding shows that group $\mathrm{S}$ is performing better compared to Yahaya et al. (2015). Group S employed smaller yarn size and different woven orientation compared to Yahaya et al. (2015). The effects of yarn size and woven orientation give an advantage to group S. Besides that, $\mathrm{S} 1$ is proposed as the best sample in terms of tensile and flexural properties compared to others. The combination of type A orientation presents better mechanical properties.

\section{Conclusion}

Generally, woven kenaf composites have shown better performance on mechanical properties compared to random chopped kenaf composites. The studies show that there was a difference of up to $199 \%$ for flexural strength, $178 \%$ for flexural modulus, $177 \%$ for tensile strength, and $84 \%$ for 


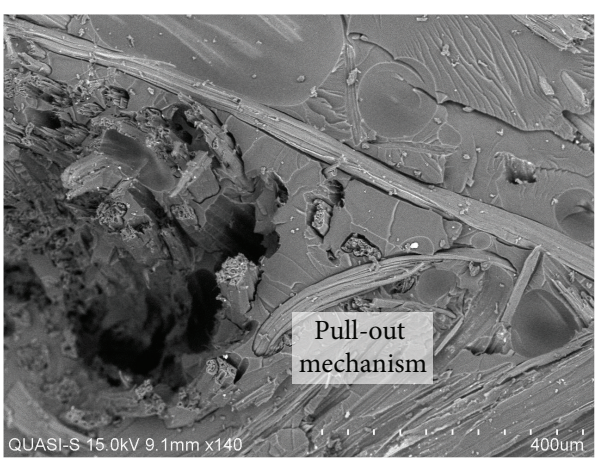

(a)

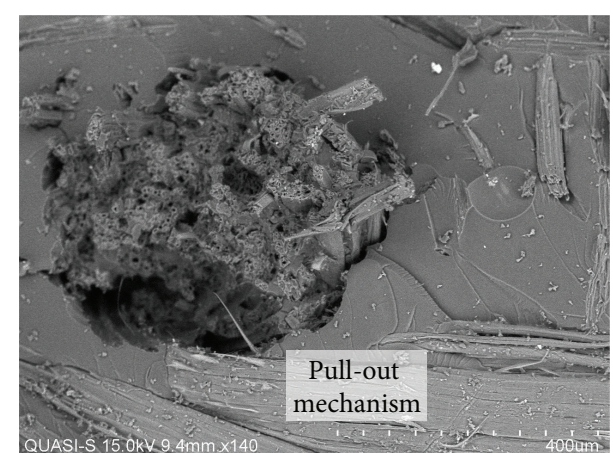

(b)

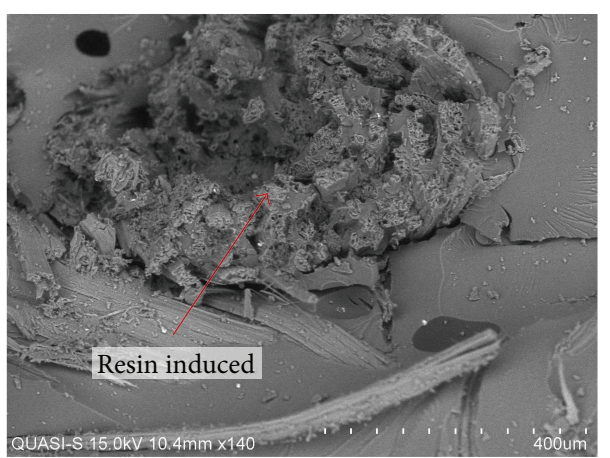

(c)

FIGURE 16: SEM analysis on sample 1 (type A) kenaf composites.

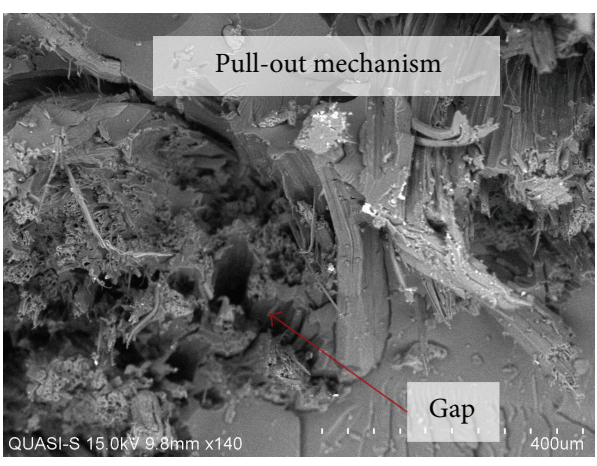

(a)

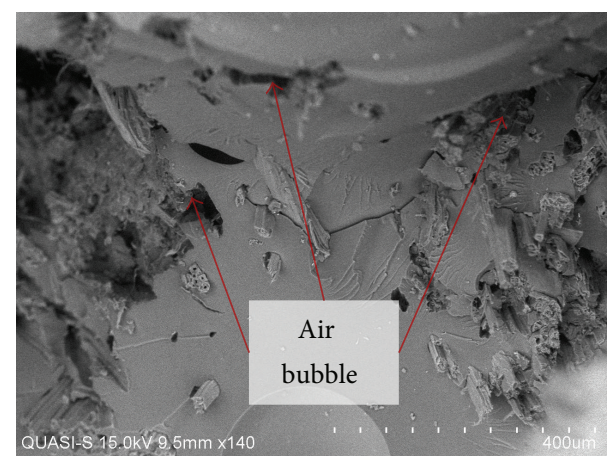

(b)

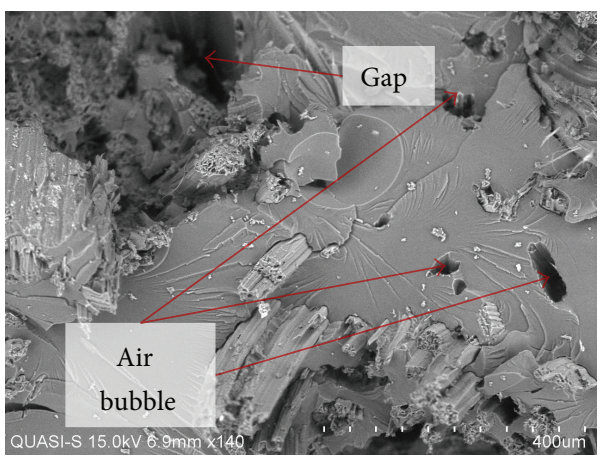

(c)

FIGURE 17: SEM analysis on sample 4 (type B) kenaf composites. 
tensile modulus for woven kenaf composites compared to random chopped kenaf composites. The yarn fibre orientation obviously influences the strength of kenaf composites. Type A layers show a higher strength compared to type B layers. The density of yarn in each woven area increases the strength of the material. S1 (type A layer) shows higher strength compared to S4 (type B layer). The fracture in the composites is dominantly due to pull-out, detaching, and debonding mechanisms between fibre and matrix epoxy interface.

The comparison analysis indicates that type A woven orientation reports higher strength compared to R1, R2, and R3. The smaller size of the yarn and the higher density of yarn in each woven area improve the strength of kenaf composites.

The mechanical properties of woven kenaf composites may not achieve the quality of reinforced glass fibre. However, the effect of fibre orientation suggests a new idea in improving the mechanical properties of woven kenaf composites in the future application.

\section{Competing Interests}

The authors declare that there are no competing interests regarding the publication of this paper.

\section{Acknowledgments}

The authors would like to thank the Ministry of Education, Malaysia, for providing Mybrain 15 grant (MyPhD) and Universiti Putra Malaysia for providing the research Grant FRGS 5524501 for this research work.

\section{References}

[1] A. Shalwan and B. F. Yousif, "In state of Art: mechanical and tribological behaviour of polymeric composites based on natural fibres," Materials \& Design, vol. 48, pp. 14-24, 2013.

[2] T. Stuart, Q. Liu, M. Hughes, R. D. McCall, H. S. S. Sharma, and A. Norton, "Structural biocomposites from flax-part I: effect of bio-technical fibre modification on composite properties," Composites Part A: Applied Science and Manufacturing, vol. 37, no. 3, pp. 393-404, 2006.

[3] K. Oksman, M. Skrifvars, and J.-F. Selin, "Natural fibres as reinforcement in polylactic acid (PLA) composites," Composites Science and Technology, vol. 63, no. 9, pp. 1317-1324, 2003.

[4] S.-H. Lee and S. Wang, "Biodegradable polymers/bamboo fiber biocomposite with bio-based coupling agent," Composites Part A: Applied Science and Manufacturing, vol. 37, no. 1, pp. 80-91, 2006.

[5] W. Liu, M. Misra, P. Askeland, L. T. Drzal, and A. K. Mohanty, “'Green' composites from soy based plastic and pineapple leaf fiber: fabrication and properties evaluation," Polymer, vol. 46, no. 8, pp. 2710-2721, 2005.

[6] D. Plackett, T. L. Andersen, W. B. Pedersen, and L. Nielsen, "Biodegradable composites based on L-polylactide and jute fibres," Composites Science and Technology, vol. 63, no. 9, pp. 1287-1296, 2003.

[7] P. Wambua, J. Ivens, and I. Verpoest, "Natural fibres: can they replace glass in fibre reinforced plastics?" Composites Science and Technology, vol. 63, no. 9, pp. 1259-1264, 2003.
[8] T. Nishino, K. Hirao, M. Kotera, K. Nakamae, and H. Inagaki, "Kenaf reinforced biodegradable composite," Composites Science and Technology, vol. 63, no. 9, pp. 1281-1286, 2003.

[9] Y. Cao, K. Goda, and Y. Wu, "Chem Ind, Mechanical properties of kenaf fibres reinforced biodegradable composites," in Proceedings of the International Conference on Advanced Fibres and Polymer Materials (ICAFPM '07), vol. 1-2, pp. 299-302, Shanghai, China, 2007.

[10] S. Ochi, "Mechanical properties of kenaf fibers and kenaf/PLA composites," Mechanics of Materials, vol. 40, no. 4-5, pp. 446452, 2008.

[11] R. Yahaya, S. M. Sapuan, M. Jawaid, Z. Leman, and E. S. Zainudin, "Effects of kenaf contents and fiber orientation on physical, mechanical, and morphological properties of hybrid laminated composites for vehicle spall liners," Polymer Composites, vol. 36, no. 8, pp. 1469-1476, 2015.

[12] O. Faruk, A. K. Bledzki, H.-P. Fink, and M. Sain, "Biocomposites reinforced with natural fibers: 2000-2010," Progress in Polymer Science, vol. 37, no. 11, pp. 1552-1596, 2012.

[13] M. M. Davoodi, S. M. Sapuan, D. Ahmad, A. Ali, A. Khalina, and M. Jonoobi, "Mechanical properties of hybrid kenaf/glass reinforced epoxy composite for passenger car bumper beam," Materials and Design, vol. 31, no. 10, pp. 4927-4932, 2010.

[14] M. Zampaloni, F. Pourboghrat, S. A. Yankovich et al., "Kenaf natural fiber reinforced polypropylene composites: a discussion on manufacturing problems and solutions," Composites Part A: Applied Science and Manufacturing, vol. 38, no. 6, pp. 1569-1580, 2007.

[15] H. M. Akil, M. F. Omar, A. A. M. Mazuki, S. Safiee, Z. A. M. Ishak, and A. Abu Bakar, "Kenaf fiber reinforced composites: a review," Materials and Design, vol. 32, no. 8-9, pp. 4107-4121, 2011.

[16] M. M. Davoodi, S. M. Sapuan, D. Ahmad, A. Aidy, and A. Khalina, "A review on natural fibre composites in automotive industry," in Research in Natural Fibre Reinforced Polymer Composite, M. S. Sapuan, Ed., pp. 247-262, UPM Press, Selangor, Malaysia, 2008.

[17] R. Yahaya, S. M. Sapuan, M. Jawaid, Z. Leman, and E. S. Zainudin, "Effect of layering sequence and chemical treatment on the mechanical properties of woven kenaf-aramid hybrid laminated composites," Materials and Design, vol. 67, pp. 173179, 2015.

[18] B. F. Yousif, A. Shalwan, C. W. Chin, and K. C. Ming, "Flexural properties of treated and untreated kenaf/epoxy composites," Materials and Design, vol. 40, pp. 378-385, 2012.

[19] R. Yahaya, S. M. Sapuan, M. Jawaid, Z. Leman, and E. S. Zainudin, "Mechanical performance of woven kenaf-Kevlar hybrid composites," Journal of Reinforced Plastics and Composites, vol. 33, no. 24, pp. 2242-2254, 2014.

[20] A. R. Azrin Hani, T. S. Chan, A. Roslan, and J. M. Mariatti, "Impact and flexural properties of imbalance plain woven coir and kenaf composite," Applied Mechanics and Materials, vol. 271-272, pp. 81-85, 2013.

[21] A. R. A. Hani, R. Ahmad, and M. Mariatti, "Influence of laminated textile structures on mechanical performance of NF-epoxy composites," International Scholarly and Scientific Research \& Innovation, vol. 7, no. 6, pp. 757-763, 2013.

[22] S. Shibata, Y. Cao, and I. Fukumoto, "Flexural modulus of the unidirectional and random composites made from biodegradable resin and bamboo and kenaf fibres," Composites Part A: Applied Science and Manufacturing, vol. 39, no. 4, pp. 640-646, 2008. 
[23] S. H. Aziz and M. P. Ansell, "The effect of alkalization and fibre alignment on the mechanical and thermal properties of kenaf and hemp bast fibre composites. Part 1. Polyester resin matrix," Composites Science and Technology, vol. 64, no. 9, pp. 1219-1230, 2004.

[24] R. Mahjoub, J. M. Yatim, A. R. Mohd Sam, and M. Raftari, "Characteristics of continuous unidirectional kenaf fiber reinforced epoxy composites," Materials and Design, vol. 64, pp. 640-649, 2014.

[25] M. N. Roslan, A. E. Ismail, M. Y. Hashim, M. H. Zainulabidin, and S. N. A. Khalid, "Modelling analysis on mechanical damage of kenaf reinforced composite plates under oblique impact loadings," Applied Mechanics and Materials, vol. 465-466, pp. 1324-1328, 2014.

[26] R. Park and J. Jang, "Stacking sequence effect of aramidUHMPE hybrid composites by flexural test method," Polymer Testing, vol. 16, no. 6, pp. 549-562, 1998. 

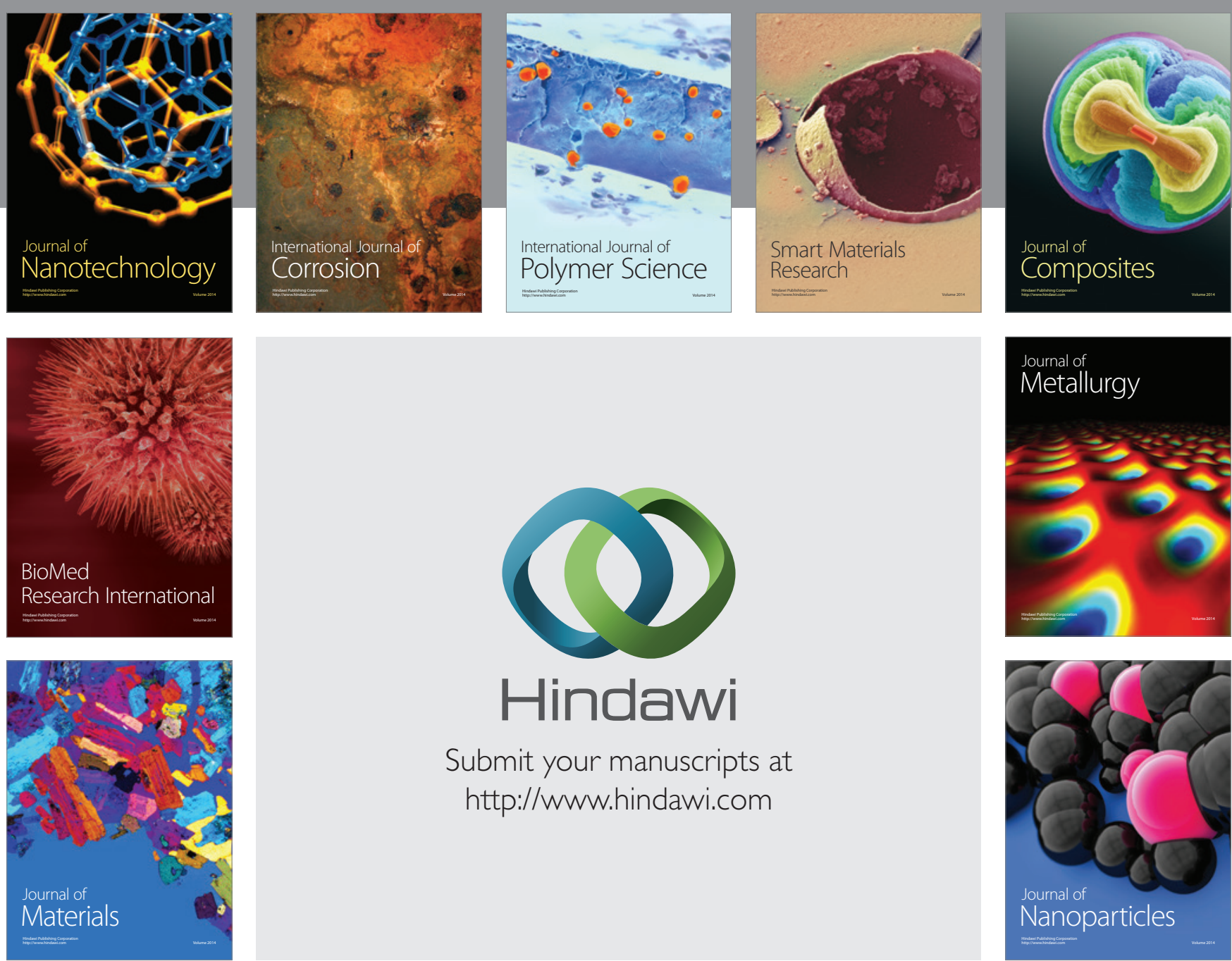

\section{Hindawi}

Submit your manuscripts at

http://www.hindawi.com

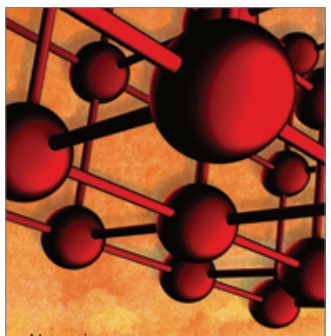

Materials Science and Engineering
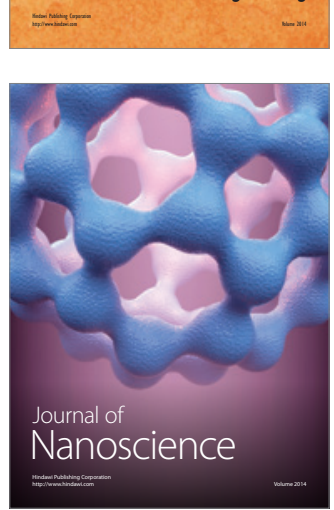
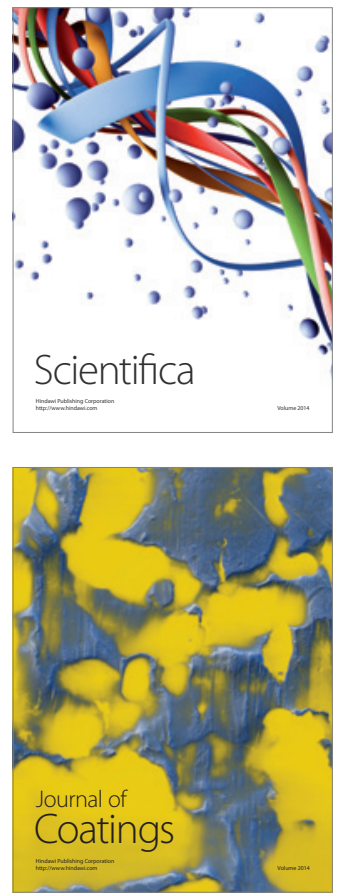
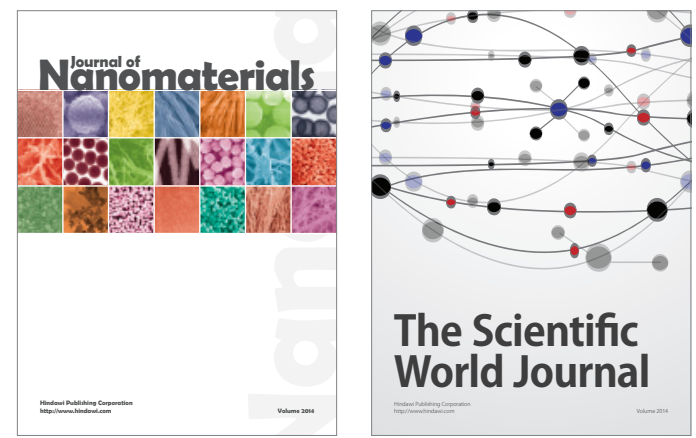

The Scientific World Journal
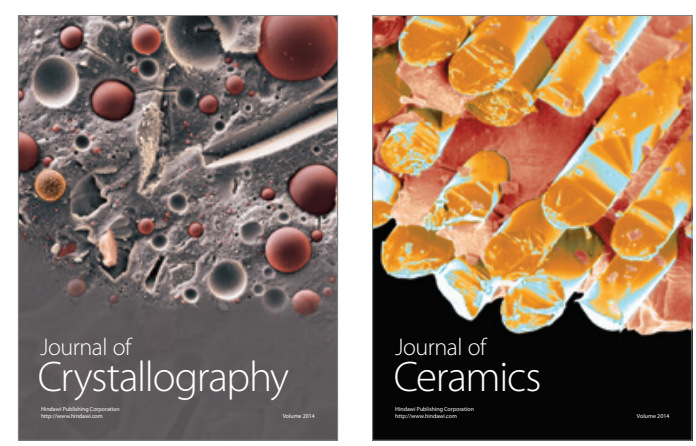
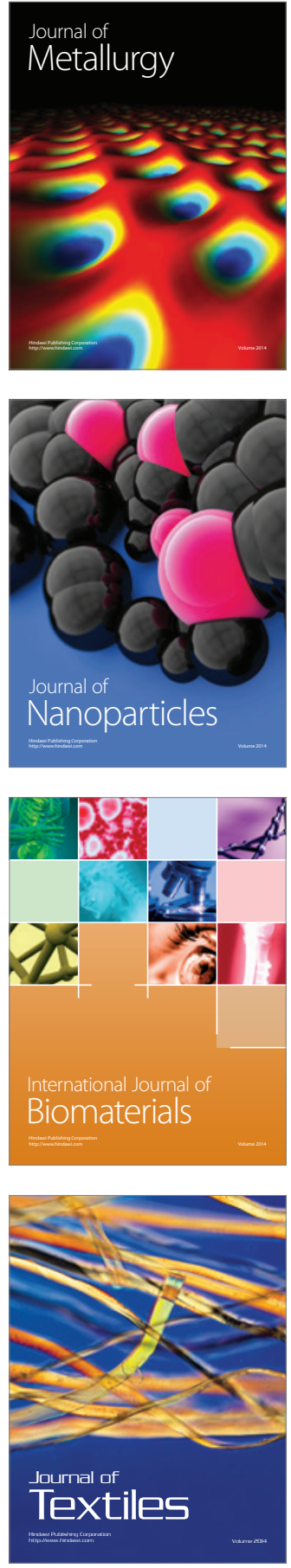